Article

\title{
Seismic Behavior of Substandard RC Columns Retrofitted with Embedded Aramid Fiber Reinforced Polymer (AFRP) Reinforcement
}

\author{
Engin C. Seyhan, Caglar Goksu *, Ahmet Uzunhasanoglu and Alper Ilki \\ Received: 12 October 2015; Accepted: 26 November 2015; Published: 2 December 2015 \\ Academic Editor: Jorge de Brito \\ Department of Civil Engineering, Civil Engineering Faculty, Istanbul Technical University, Ayazaga, Sariyer, \\ Istanbul 34469, Turkey; ecseyhan@yahoo.com (E.C.S.); ahmetuzunhasanoglu@gmail.com (A.U.); \\ ailki@itu.edu.tr (A.I.) \\ * Correspondence: goksuc@itu.edu.tr; Tel.: +90-212-285-3795; Fax: +90-212-285-6106
}

\begin{abstract}
Many existing reinforced concrete structures were constructed with substandard characteristics. Low quality concrete, poor transverse reinforcement details and insufficient flexural strength are among the most common deficiencies. While substandard structures are in need of retrofitting, particularly in seismic areas, problems such as high costs and disturbance to occupants are major obstacles for retrofit interventions. Fiber reinforced polymers can provide feasible retrofit solutions with minimum disturbance to occupants. In this study, the basic aim is to investigate the flexural seismic performance of substandard reinforced concrete columns retrofitted with embedded longitudinal fiber reinforced polymer reinforcement without increasing the original dimensions of the columns. In the experimental study, the reference and retrofitted columns were tested under constant vertical and reversed cyclic lateral loads. Three different connection methods of aramid fiber reinforced polymer reinforcement to the footing were investigated experimentally. A significant enhancement was obtained in lateral flexural strength through the proposed retrofitting method. Furthermore, it was observed that the cyclic lateral drift capacities of the retrofitted columns were as high as $3 \%$, which can be deemed as quite satisfactory against seismic actions. The comparison of the experimental data with analytical calculations revealed that a conventional design approach assuming composite action between concrete and fiber reinforced polymer reinforcement can be used for flexural retrofit design. Experimental results also demonstrated that strain limit for longitudinal fiber reinforced polymer (FRP) reinforcement should be remarkably lower in case of reversed cyclic loading conditions.
\end{abstract}

Keywords: aramid; flexure; FRP reinforcement; reinforced concrete; retrofitting; seismic

\section{Introduction}

Many substandard reinforced concrete (RC) structures should be seismically retrofitted to reduce their vulnerabilities against seismic actions. Financial constraints, disturbance to the occupants and disruption of functions of the structures are the main obstacles for proper seismic retrofitting of these substandard existing structures. In recent years, use of fiber reinforced polymers (FRP) in construction industry has become quite common. They offer feasible and innovative solutions for seismic retrofitting due to their lightweight, high tensile strength and noncorrosive character [1-6]. FRPs are also utilized as external tendons for strengthening concrete structures [7-9]. While there are many studies on external confinement of columns or joints [10-26], and on flexural retrofit with near surface mounted (NSM) FRP rods or pultruded strips under monotonic loading conditions [27-42], only few studies are available on flexural retrofitting using FRPs under repeated 
loading conditions [43-45]. According to the best knowledge of the authors', reversed cyclic flexural behavior of RC members strengthened with longitudinal FRP reinforcement was studied for the first time by Ilki and Kumbasar [46]. More recently, Bournas and Triantafillou [47], Goksu et al. [48], Fahmy and $\mathrm{Wu}$ [49], Vrettos et al. [50], Li et al. [51], Goksu et al. [52] and Faustino and Chastre [53] also studied this type of behavior. However, in all cases, except the studies of Goksu et al. [48,52], it is difficult to perceive the performance of the NSM FRP system and anchoring of NSM reinforcement into the footing in case of low strength concrete. In the study of Goksu et al. [48], which was the precursor of this study, the possibility of using carbon FRP (CFRP) longitudinal (rod, laminate, sheet) and transverse (sheet) reinforcement for the flexural seismic retrofit of low strength RC members under reversed cyclic loading conditions was investigated. The aim of flexural retrofitting by using FRP reinforcement, mainly in the longitudinal direction, was to obtain flexural strength enhancement under reversed cyclic loading, since many existing structures, among other deficiencies, suffer from lack of sufficient flexural strength in case of seismic loading. Furthermore, it was targeted not to sacrifice from drift capacity, since drift capacity is as important as strength in case of seismic actions. In the study of Goksu et al. [48], an enhancement in flexural capacity was obtained until large drift ratios (approximately 6\% drift ratio) through flexural FRP retrofit. Moreover, after testing of performance of several anchorage types for connection of FRP reinforcement to the footing, the most effective anchorage detail was obtained, and was also utilized in the current testing program. The major differences between the current testing program and the work reported by Goksu et al. [48] are (i) the presence of axial load ( $20 \%$ of axial load capacity of the columns, whereas no axial load was applied on the specimens in the study of Goksu et al. [48]), (ii) the different type of FRP reinforcement utilized in the current study, aramid FRP pultruded laminates (AFRP), and (iii) intentional partial debonding of FRP reinforcement in the anchorage hole to allow more distributed FRP deformations at the critical interface between the column and footing in the current study. The reason of utilizing AFRP reinforcement rather than CFRP or GFRP in the current study is the expectation of potentially better performance of AFRP due to its better toughness characteristics [54].

In this study, four cantilever RC columns were constructed using low strength concrete and plain reinforcing bars for representing relatively old substandard structures. According to the compressive tests of core specimens extracted from many different existing buildings constructed before 1990s in Turkey, the concrete compressive strengths are found to be between 5 and $13 \mathrm{MPa}$. The microstructural analyses of these core specimens revealed that the concretes were very porous and the water/cement ratio used for making them was excessively high [55]. The columns were then tested under reversed cyclic lateral and constant axial loads before and after retrofitting. Three different anchorage details were designed for embedding AFRP laminates to the existing footing. These different details constitute the main test variable. While the applied retrofitting technique is similar to NSM technique in terms of mechanical contribution of FRP reinforcement to the flexural strength, application technique of retrofitting is different than NSM technique, as has been introduced by Goksu et al. [48] before. As is well known, concrete cover is generally deteriorated due to corrosion of internal steel reinforcing bars of substandard structures constructed with low strength concrete. Typical appearances of columns of existing substandard RC frame buildings with corroded reinforcement are shown in Figure 1.

In the applied retrofitting technique, firstly, deteriorated concrete cover is removed. Secondly, a layer of high strength structural repair mortar (SRM) is applied to obtain a flat surface for bonding AFRP reinforcement. After hardening of SRM, AFRP longitudinal reinforcement is bonded to the substrate by using epoxy adhesive. Then, a second layer of SRM is applied to form the new concrete cover. As the final stage of seismic retrofit, the strengthened column is externally jacketed with CFRP sheets in transverse direction. Consequently, by this technique, all retrofitting application was conducted within the thickness of the original concrete cover, which may be deemed as an advantage with respect to the conventional retrofitting techniques. Clearly, AFRP reinforcement, 
which is embedded into SRM, is expected to perform better than NSM application in case of poor quality concrete in terms of structural integrity.
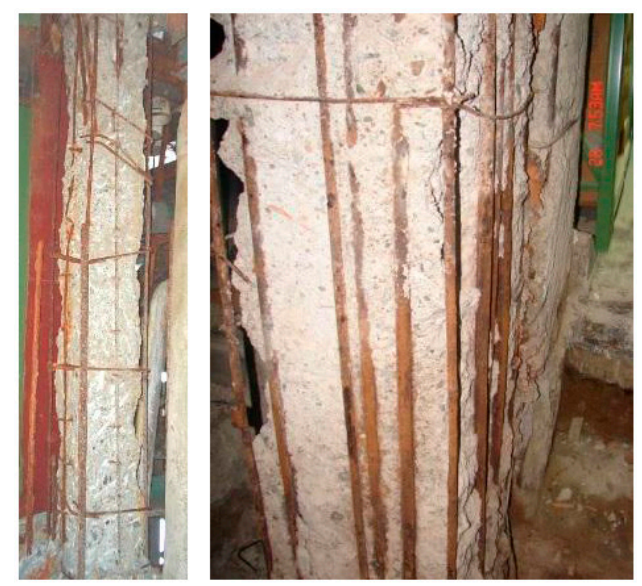

Figure 1. The appearances of existing substandard columns of RC frame structures.

Test results, supported by the analytical calculations, revealed that the cyclic flexural capacity of the substandard RC members can be increased significantly by the use of AFRP pultruded laminates through the applied retrofitting method. Current technical guidelines/documents do not allow use of longitudinal FRP reinforcement for flexural retrofit under cyclic loading in potential plastic hinge regions of RC members $[5,56,57]$. This is basically due to concerns related with ductility. In this study, however, it was observed that the deformation capacity of the retrofitted columns was also acceptable for a satisfactory seismic performance.

It was observed from the seismic tests that the measured rupture strain of AFRP reinforcement, which was subjected to cyclic loading, was approximately $43 \%$ of design rupture strain of FRP reinforcement (design rupture strain of FRP reinforcement $=$ environmental reduction factor $\times$ manufacturer declared ultimate rupture strain). For NSM applications under monotonic loading conditions, ACI 440-2R-08 [5] recommends to consider $70 \%$ of ultimate strain of FRP. In this study, it is demonstrated clearly that allowable strain limit for longitudinal FRP reinforcement should be lower in case of reversed cyclic loading conditions (only $43 \%$ of manufacturer declared ultimate strain of FRP reinforcement). It is also shown that the increased flexural capacity as well as nonlinear inelastic displacement response of columns after strengthening could be predicted satisfactorily using conventional RC theory.

\section{Experimental Program}

The aim of the applied retrofitting technique is the enhancement of column flexural capacity using AFRP reinforcement under cyclic lateral loading in the presence of constant axial load without a significant sacrifice from deformation capacity. On the other hand, like many existing substandard $\mathrm{RC}$ columns, the spacing of the transverse reinforcement of the columns was insufficient. This might have caused deficiencies in terms of ductility and shear strength after flexural strength enhancement through FRP retrofitting. Therefore, after the intervention made for flexural strength enhancement through longitudinal AFRP reinforcement, the columns were also jacketed externally with CFRP sheets in transverse direction. As known, while external FRP confinement has a remarkable contribution to deformability and shear strength, its contribution to flexural strength (which is the main issue investigated in this study) is marginal with respect to the contribution of longitudinal AFRP reinforcement. Nevertheless, both contributions were taken into account during the analytical calculations presented in this paper. 


\subsection{Description of Test Specimens}

Four substandard symmetrically reinforced cantilever RC columns were tested under reversed cyclic lateral and constant axial load. The main features of the specimens are shown in Table 1. While lateral loads were applied through displacement cycles in pushing and pulling directions with increasing amplitudes, axial load was kept constant. All columns were identical (before retrofitting) and flexure-critical.

Table 1. Main Features of the Specimens.

\begin{tabular}{|c|c|c|c|c|}
\hline Specimen & $\begin{array}{l}\text { Main longitudinal AFRP a } \\
\text { reinforcement }\end{array}$ & $\begin{array}{l}\text { Additional anchorage } \\
\text { reinforcement }{ }^{\text {a }}\end{array}$ & Anchorage type ${ }^{a}$ & $\begin{array}{c}\text { Transverse CFRP } \\
\text { reinforcement }\end{array}$ \\
\hline REF & - & - & - & - \\
\hline LAM & $2 \times 2($ each $42 \mathrm{~mm} \times 1.4 \mathrm{~mm})$ & - & Fully bonded & 2 plies $\times 0.166 \mathrm{~mm}$ \\
\hline LAM-PB & $2 \times 2($ each $42 \mathrm{~mm} \times 1.4 \mathrm{~mm})$ & - & Partially bonded & 2 plies $\times 0.166 \mathrm{~mm}$ \\
\hline LAM-LAM & $2 \times 2($ each $42 \mathrm{~mm} \times 1.4 \mathrm{~mm})$ & $2 \times 2($ each $42 \mathrm{~mm} \times 1.4 \mathrm{~mm})$ & Fully bonded & 2 plies $\times 0.166 \mathrm{~mm}$ \\
\hline
\end{tabular}

The geometry and the reinforcement details of the columns are presented in Figure 2. In this figure, it can be observed that the longitudinal bars were $(4 \phi 14)$ continuous from the bottom of the footing to the top of the column. The spacing of transverse bars was $200 \mathrm{~mm}$ in the testing zone $(\phi 10 / 200)$. All internal reinforcing bars were plain round bars, which had been used commonly until 2000s in Turkey.

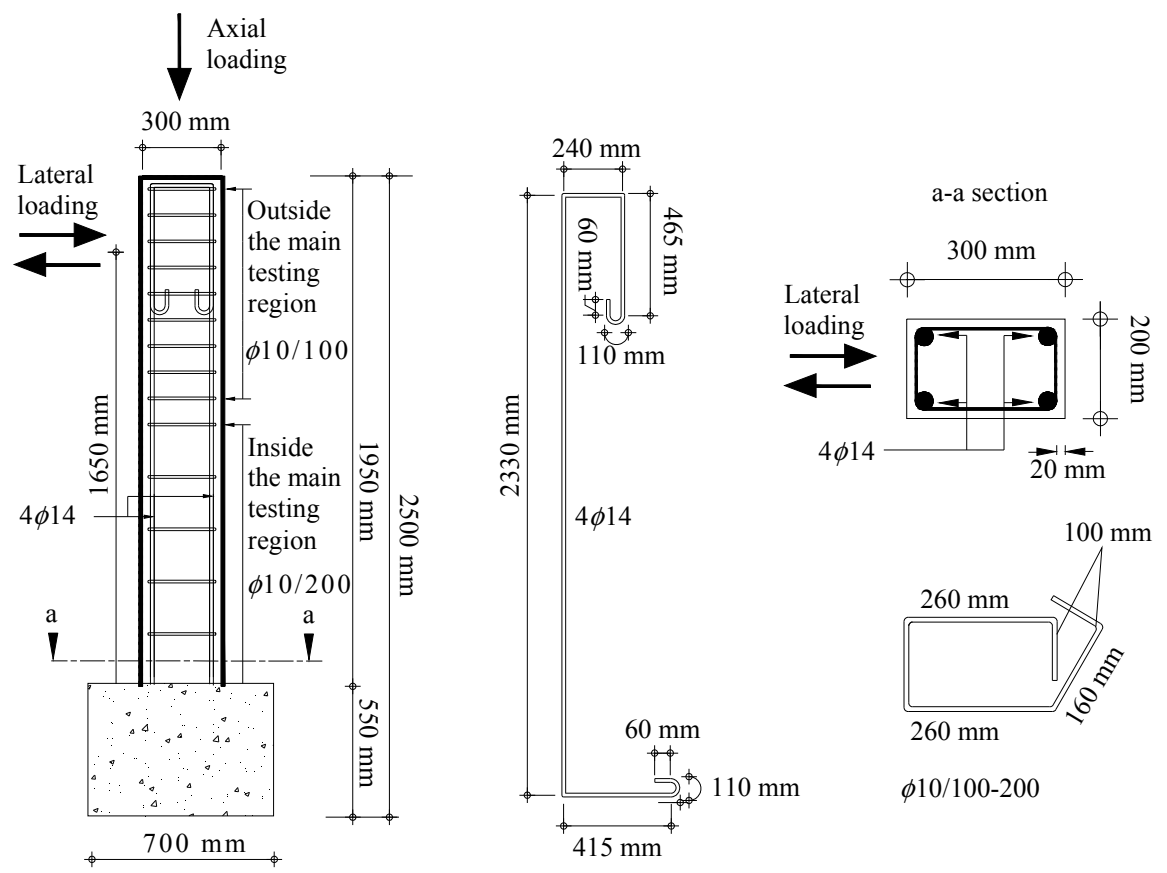

Figure 2. The geometry and reinforcement details of the columns.

The reference specimen, denoted as REF, was tested without any retrofit. The other columns (LAM, LAM-LAM and LAM-PB) were tested after they were retrofitted with AFRP reinforcement in longitudinal and CFRP reinforcement in transverse directions. The longitudinal AFRP reinforcement embedded in the columns was anchored directly to the footing in all retrofitted specimens, while additional AFRP anchorage reinforcement was used for the specimen LAM-LAM to achieve a better performance by avoiding potential failures of FRP reinforcement at the interface of the column and the footing. Contrary to the fully bonded anchorages of longitudinal FRP reinforcement in case of 
the specimens LAM and LAM-LAM, the anchorage of the FRP reinforcement in case of the specimen LAM-PB was intentionally partly debonded from concrete using insulating tape. Partial debonding of AFRP reinforcement in the anchorage zone was for preventing the localized damage of the AFRP reinforcement at the interface of column and footing by avoiding localization of stresses at this critical zone. Details on each retrofitting scheme are explained below and presented in Figure 3.

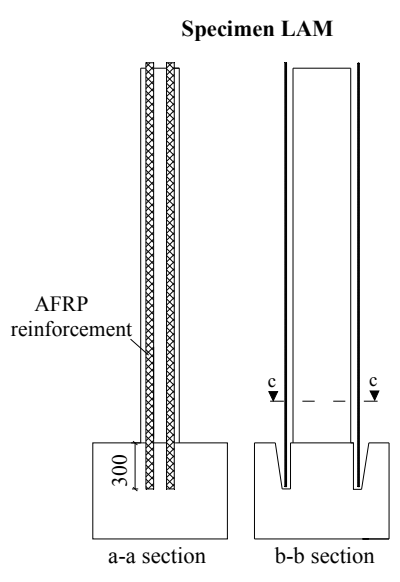

Specimen LAM
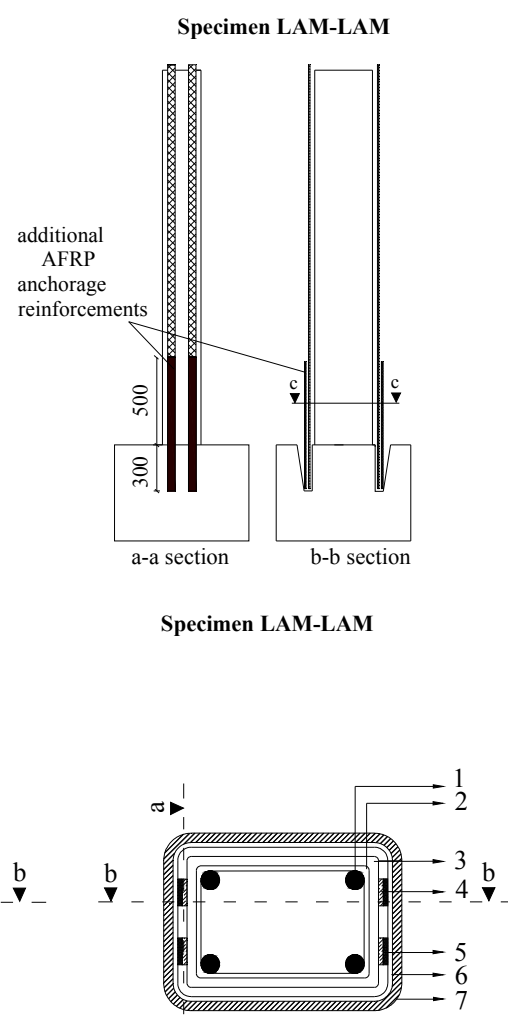

๘)

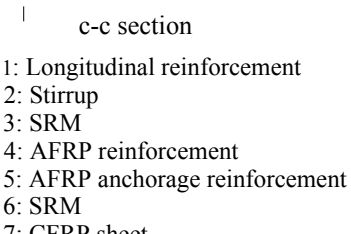

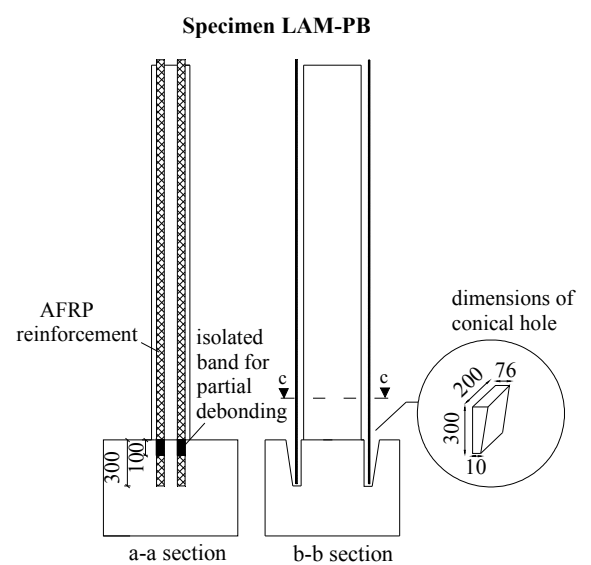

Specimen LAM-PB

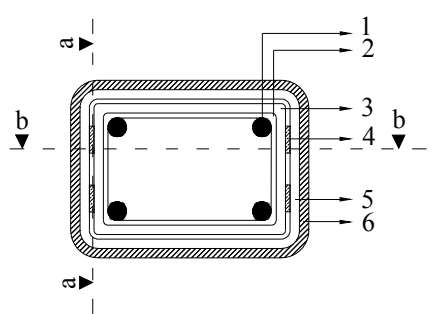

c-c section

1: Longitudinal reinforcement 2: Stirrup

3: SRM

4: Partially bonded AFRP reinforcement

5: SRM

6: CFRP sheet

Figure 3. The retrofit schemes of the specimens (Note: Dimensions in mm).

\subsection{Characteristics of Materials}

Low strength concrete and plain reinforcing bars were used for the construction of the columns for representing relatively old, existing substandard structures. All RC columns were cast at the same day, from the same concrete production batch. The 28th-day average compression strength was measured as $10.3 \mathrm{MPa}$. An additional compressive strength test, performed on the 750th day, yielded an average compressive strength of $15.2 \mathrm{MPa}$. The compressive strength, at the time of testing of columns (between 57th and 64th days), was calculated as $12.0 \mathrm{MPa}$, according to the procedure described in Eurocode 2-Part 1 (2004) [58]. For the numerical analysis, this value was multiplied with 0.85 to account for the size effect in concrete columns. The concrete mix-proportions of cement: aggregate $(0-4 \mathrm{~mm})$ : aggregate $(5-12 \mathrm{~mm})$ : sand: water were 1:3.8:2.2:4.7:1 (by weight). The yield stress $\left(f_{\mathrm{y}}\right)$ and tensile strength $\left(f_{\max }\right)$ of longitudinal bars were 296 and $400 \mathrm{MPa}$, while those of transverse bars were 315 , and $400 \mathrm{MPa}$, respectively. The compression tests of concrete specimens and tension tests of steel bars were carried out in accordance with TS-EN Turkish Standards 12390-3 [59] and TS 708 [60], respectively. Two different types of FRP reinforcement were used in retrofitting; 
AFRP pultruded laminates in longitudinal and CFRP sheets in transverse direction. The appearance and geometrical and mechanical properties of FRP reinforcement are presented in Figure 4 and Table 2 , respectively. In this table, $t_{\mathrm{f}}, w_{\mathrm{f}}, E_{\mathrm{f}}$ and $\varepsilon_{\mathrm{fu}}{ }^{*}$ are the effective thickness, the effective width, the tensile elastic modulus and the ultimate rupture strain of FRP reinforcement declared by the manufacturer (BASF Construction Chemicals, Augsburg, Germany). The compressive strengths of SRM (cement based structural repair mortar, EN-1504-3 [61]) used for forming the new concrete cover, the epoxy adhesive used for bonding the AFRP reinforcement to the column surface (EN-1504-4 [62]), the epoxy adhesive used for bonding CFRP sheets in transverse direction to the column surface, and the epoxy grout used for anchoring AFRP reinforcement in the footing were 50, 75, 60 and $80 \mathrm{MPa}$ (obtained from $40 \mathrm{~mm} \times 40 \mathrm{~mm} \times 160 \mathrm{~mm}$ prism test results at 7 days of age), respectively. The compressive characteristics of all materials were determined according to TS-EN 196-1 [63], and the mechanical characteristics of CFRP sheets were determined according to ASTM D3039 [64].

Table 2. Properties of FRP reinforcement.

\begin{tabular}{ccccc}
\hline FRP reinforcement & $\boldsymbol{E}_{\mathrm{f}}\left(\mathbf{N} / \mathbf{m m}^{\mathbf{2}}\right)$ & $\boldsymbol{t}_{\mathrm{f}}(\mathbf{m m})$ & $w_{\mathrm{f}}(\mathbf{m m})$ & $\varepsilon_{\mathbf{f u}}{ }^{*}$ \\
\hline AFRP (laminate) & 60,000 & 1.4 & 42 & 0.023 \\
CFRP (sheet) & 230,000 & 0.166 & 500 & 0.015 \\
\hline
\end{tabular}

FRP, fiber reinforced polymers; AFRP, aramide reinforced polymers; CFRP, carbon reinforced polymers; $E_{\mathrm{f}}$, tensile elastic modulus of FRP reinforcement; $t_{\mathrm{f}}$, effective thickness of FRP reinforcement; ; $w_{\mathrm{f}}$, effective width of FRP reinforcement; $\varepsilon_{\mathrm{fu}}{ }^{*}$, ultimate rupture strain of FRP reinforcement declared by manufacturer.
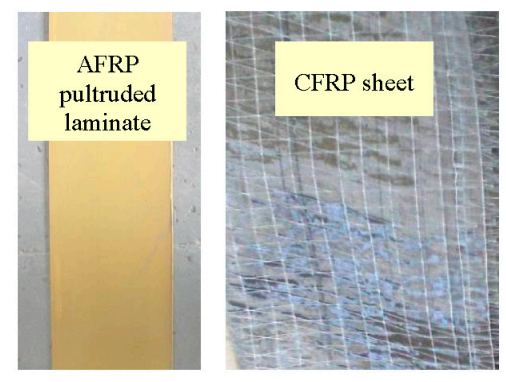

Figure 4. The appearances of longitudinal AFRP and transverse CFRP reinforcement.

\subsection{Retrofitting Procedure}

For enhancing the column flexural capacity, three specimens were retrofitted with longitudinal AFRP reinforcement, which was embedded within the concrete cover (after removal of poor concrete cover), and anchored to the existing footing. The retrofitting details and the application stages are shown in Figures 3 and 5 respectively. As a first step, the concrete cover was removed for more effective utilization of AFRP reinforcement until the longitudinal steel bars were exposed (Figure 5a). This allowed AFRP reinforcement to be embedded within the cover thickness. This application may also cover a corrosion repair procedure, which is generally required in case of rehabilitation of old buildings, which were constructed with poor quality concrete. Then, a thin layer of SRM was applied to obtain a sound and smooth substrate over the internal steel reinforcing bars (Figure 5b). Afterwards, an epoxy-based primer was applied over the SRM to increase the adhesion between the AFRP reinforcement and SRM. Then, two pultruded AFRP laminates of $1.4 \mathrm{~mm}$ thickness and $42 \mathrm{~mm}$ width were placed symmetrically on each side of the columns in the strong direction, with an anchorage length of $300 \mathrm{~mm}$ (Figures 3 and 5c), and the laminates were bonded to the substrate by using an epoxy adhesive. For the connection of the AFRP longitudinal reinforcement to the footing, conical holes were dug in the footing (Figure 3). The longitudinal AFRP reinforcement embedded in the columns was anchored directly to the footing in all retrofitted specimens. Different from the specimen LAM, for the specimen LAM-PB, the top $100 \mathrm{~mm}$ long part of the AFRP 
reinforcement in the conical hole was wrapped with a plastic insulating band in order to create a partially debonded anchor (Figures 3 and $5 \mathrm{~d}$ ). Therefore, total bonded lengths of the AFRP reinforcement in the footing were $200 \mathrm{~mm}$ (rather than $300 \mathrm{~mm}$ ) for the specimen LAM-PB. Additional AFRP anchorage reinforcement of $800 \mathrm{~mm}$ length was used at the column-footing interface in case of the specimen LAM-LAM (Figures 3 and 5e). The $300 \mathrm{~mm}$ long part of the additional AFRP anchorage reinforcement was embedded into the conical hole. AFRP anchorage reinforcement and the main AFRP reinforcement were bonded to each other by using the same epoxy adhesive, and they were anchored to the footing (in the pre-dug conical hole) together by using epoxy grout. Same epoxy grout was used to fill the conical holes in the footings of specimens LAM and LAM-PB. After all, a layer of SRM was applied to bring the column cross-section to its original dimensions (Figure 5f). It should be noted that, buckling of NSM FRP bars was observed during the reversed cyclic tests carried out by Bournas and Triantafillou [47]. Therefore, after installation of longitudinal AFRP reinforcement and formation of concrete cover with SRM, as a final step, CFRP sheets were wrapped around the columns in transverse direction to enhance the deformability through confinement action and to avoid potential shear damages due to increased flexural strength as well as to prevent buckling of AFRP reinforcement in compression (Figure 5g). Additionally, CFRP confinement is believed to enhance the bond between the core concrete, SRM and AFRP reinforcement. Consequently, the external dimensions of the reference and retrofitted specimens were identical $(200 \mathrm{~mm} \times 300 \mathrm{~mm})$. In other words, all retrofitting application was conducted within the thickness of the original concrete cover. Naturally, during practical applications, the safety of the footing and soil under the footing should be checked to confirm that they have also sufficient safety margin against increased internal forces.

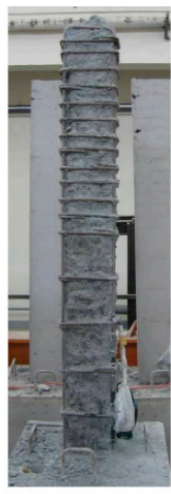

(a)

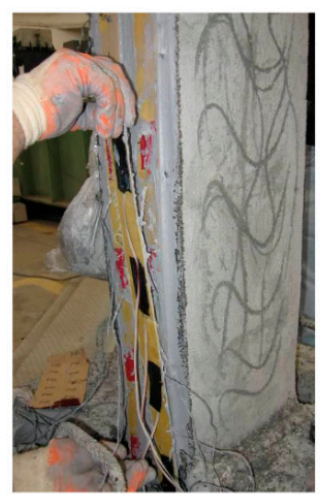

(e)

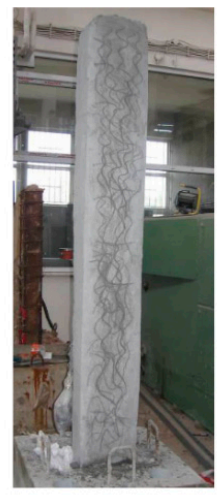

(b)

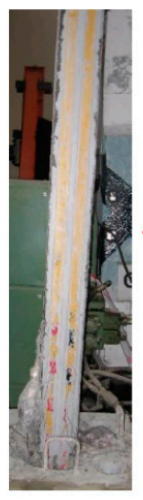

(c)

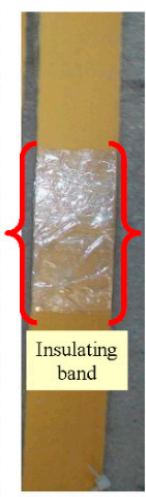

(d)

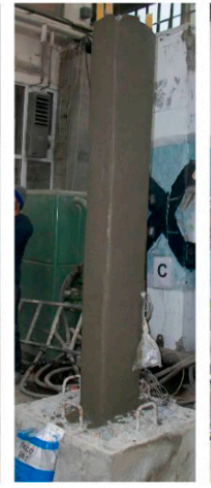

(f)

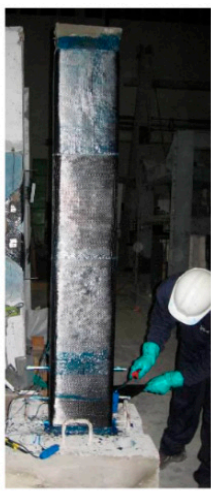

(g)

Figure 5. (a) Removal of cover concrete, (b) application of a thin layer of cement based SRM to obtain a flat surface, (c) installation of the AFRP pultruded laminates, (d) laminate with isolated band (only for the specimen LAM-PB), (e) application of additional AFRP laminate anchorages (only for the specimen LAM-LAM), (f) application of last layer of structural repair mortar, and (g) wrapping with CFRP sheets in transverse direction. 


\subsection{Test Setup}

The specimens were tested under constant axial load and reversed cyclic lateral loads in a quasi-static displacement-controlled manner. A displacement-based loading protocol was applied during testing of all specimens. Similar loading patterns were used by Matamoros and Sozen [65], Iacobucci et al. [13], Ilki et al. [20], Bournas and Triantafillou [66], and Goksu et al. [48] during testing of RC columns. Target lateral drift ratios were calculated as the ratio of the lateral displacement to the specimen height (at which actuator is connected) in both pushing and pulling directions (Figure 6). The axial load of $120 \mathrm{kN}$, which corresponded to $20 \%$ and $18 \%$ of the axial load capacity of the reference column without and with consideration of the capacity of the internal steel reinforcement, respectively, was applied to all specimens (Figure 7a). Other than a large number of displacement transducers, a number of strain gauges were also used on steel bars and AFRP reinforcement in longitudinal direction and on stirrups in transverse direction (Figure $7 \mathrm{~b}$ ).

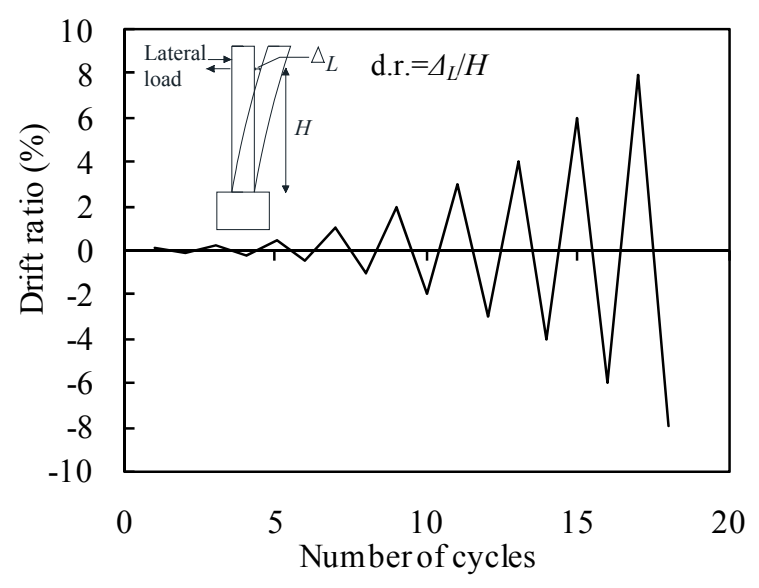

Figure 6. Loading protocol of the columns.

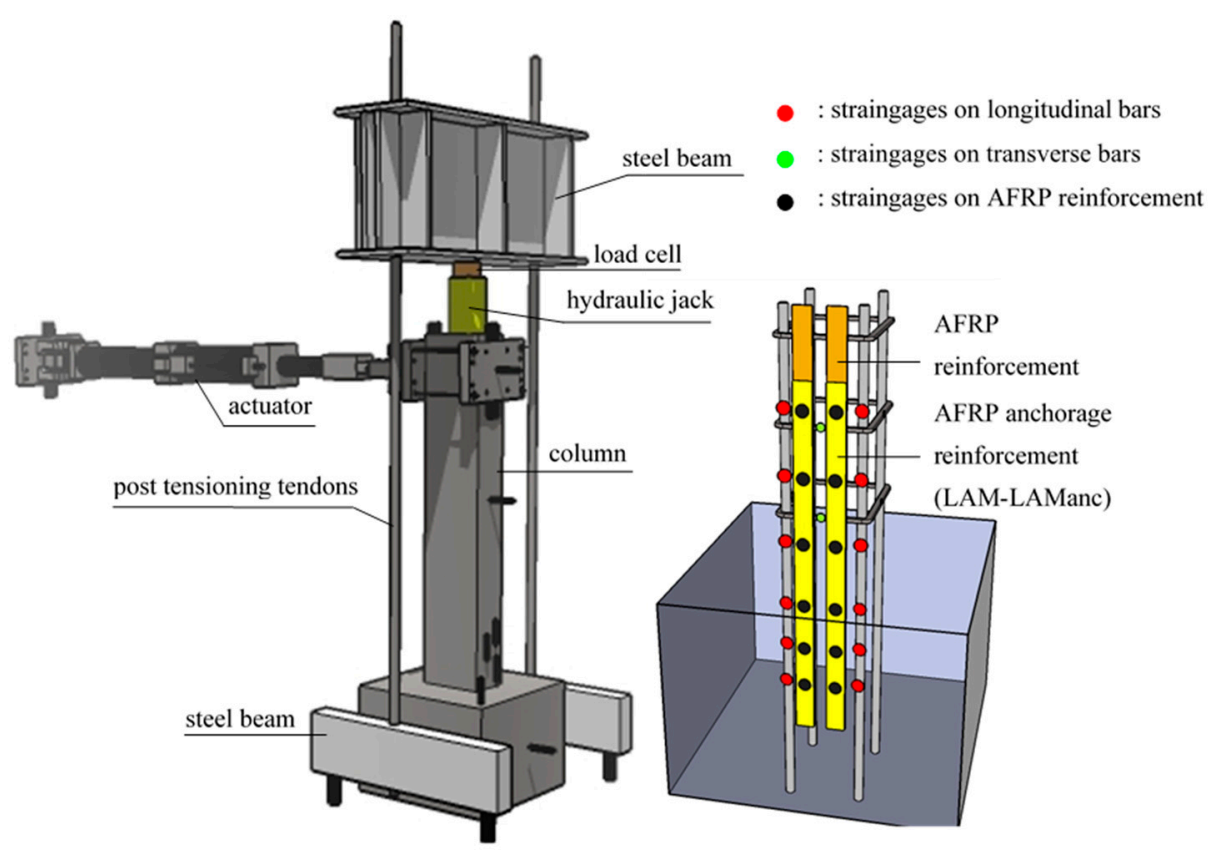

(a)

(b)

Figure 7. (a) The testing setup; and (b) Strain gauges on steel bars and AFRP reinforcement. 


\section{Analytical Considerations}

\subsection{Theoretical Flexural Strength and Displacement Capacity before and after Retrofit}

The theoretical strength and local deformation characteristics are determined through moment-curvature relationships obtained by fiber analysis approach using the stress-strain relationships of materials representing monotonic increasing stresses. The monotonic moment-curvature relationships are obtained using XTRACT (2007) [67] software at the critical sections of each column for predicting the load-displacement relationships of the columns. Therefore, the theoretical load-displacement relationships approximately represent the envelopes of hysteretic curves. The effect of axial load is considered while obtaining the moment-curvature relationships. In the moment-curvature analysis, steel reinforcing bars are assumed to behave in an elasto-plastic manner with strain hardening. The stress-strain relationship of the steel reinforcing bar is defined according to actual uniaxial tension test results. Longitudinal AFRP reinforcement is taken into account as linear elastic material in tension since the buckling and debonding of AFRP reinforcement during cyclic loading is prevented by SRM and CFRP confinement. Nevertheless, the contribution of the AFRP reinforcement in compression is neglected. Since the retrofitted specimens, thereby the AFRP applications, were exposed to laboratory conditions for a very short time prior to testing, the design rupture strain of AFRP reinforcement $\left(\varepsilon_{\mathrm{fu}}\right)$ is assumed to be equal to $\varepsilon_{\mathrm{fu}}{ }^{*}$, which is the manufacturer declared ultimate strain of FRP reinforcement (Equation (1)). In other words, the environmental reduction factor, $C_{\mathrm{E}}$, is taken as 1.0. While ACI 440-2R-08 [5] recommends to reduce $\varepsilon_{\mathrm{fu}}$ by a factor of 0.70 for NSM FRP applications under monotonic flexural loading, $\varepsilon_{\mathrm{fu}}$ is reduced by a factor of 0.43 during the analysis presented here (the reason for this assumption is explained in the section titled "Strains of Steel and AFRP Reinforcement"). For obtaining the stress-strain relationship of CFRP confined concrete, the model proposed by Ilki et al. [68] is used. The stress-strain relationship of CFRP confined concrete is obtained for two different parts of the confined cross-section (for core concrete confined by transverse steel bars and external CFRP, and for SRM as concrete cover confined by only external CFRP). The stress-strain relationships of unconfined concrete, core concrete, SRM, internal steel and AFRP reinforcement used in calculation of moment capacities are presented in Figure 8. The marks in the figure correspond to the analytical values of the specimens during analysis. It should be noted that SRM causes an increase of $7 \%$ in theoretical moment capacity, while both SRM and AFRP cause an increase of 51\% and $97 \%$ for the specimens LAM and LAM-LAM, respectively, in theoretical moment capacity in comparison with the reference column. The moment-curvature analysis is terminated when longitudinal FRP reinforcement ruptures (Figure 9).

$$
\varepsilon_{\mathrm{fu}}=C_{\mathrm{E}} \cdot \varepsilon_{\mathrm{fu}}{ }^{*}
$$

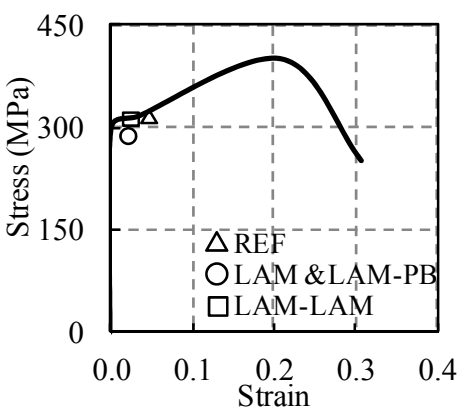

(a)

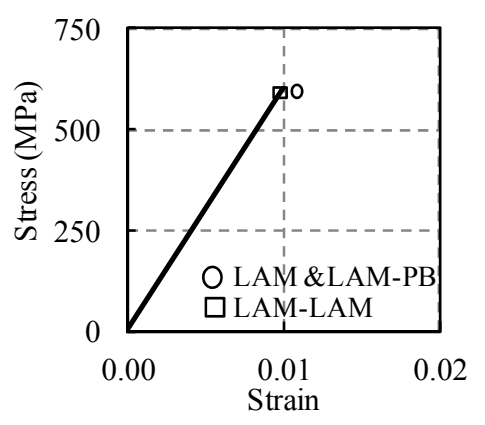

(b)

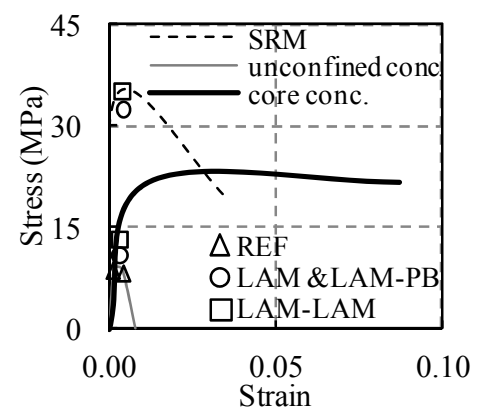

(c)

Figure 8. The theoretical stress-strain relationships of the (a) Internal steel reinforcement; (b) AFRP reinforcement; and (c) Concrete (conc., concrete). 


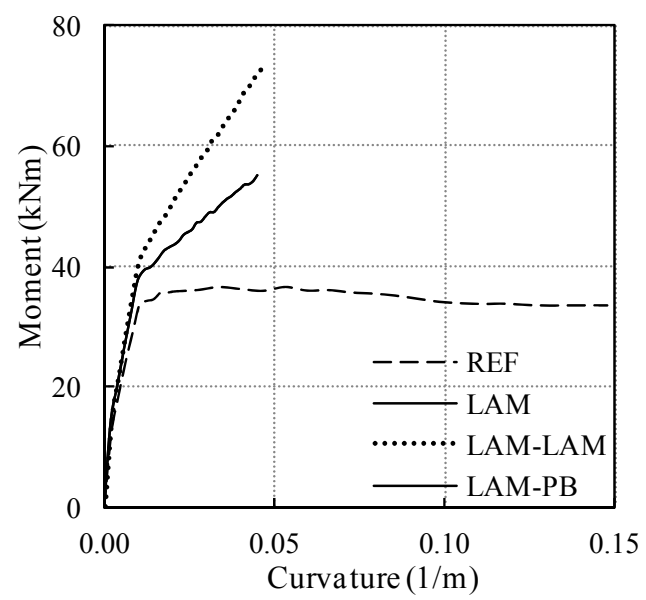

Figure 9. Theoretical moment-curvature relationships. (Note: The moment-curvature relationships for the specimens LAM and LAM-PB are the same).

After obtaining the moment-curvature relationships through fiber analysis approach with summarized assumptions, the total top displacements $\left(\delta_{t}\right)$ of the columns are determined considering the elastic and inelastic deformations. It should be noted that the shear deformations are neglected since they are very small with respect to contribution of flexure. As a first step, for calculating the yield displacements $\left(\delta_{\mathrm{y}}\right)$ of the columns using Equation (2), the columns are discretized into 5 elements for considering effective flexural stiffness, rather than the gross cross-sectional stiffness, at different heights of the column as a function of bending moment when the longitudinal reinforcing bars yield at the critical maximum moment region (Figure 10). In Equation (2), $\chi_{i}$ is the elastic curvature (corresponding to respective bending moment on that discretized part), $l_{i}$ is the length of the respective part, and $h_{i}$ is the distance between the center of the respective part and the tip of the column, where the lateral load is applied. Sequentially, for obtaining the plastic component of the total top displacements $\left(\delta_{\mathrm{p}}\right)$ of the columns, conventional plastic hinge approach is used (Equation (3)). In Equation (3), $\chi_{\mathrm{p}}$ is the plastic curvature at the plastic hinge of the column, $l_{\mathrm{p}}$ is the plastic hinge length, $H$ is the distance between the interface of the column and the footing and the point of application of the lateral load. The length of plastic hinge $\left(l_{\mathrm{p}}\right)$ of the column is assumed as $h / 2(150 \mathrm{~mm})$ according to TSDC [57], where $h$ refers to the depth of the cross-section of the column. Finally, the total top displacements $\left(\delta_{t}\right)$ of the columns are determined using Equation (4). The theoretical lateral load-displacement relationships are then obtained and compared with the experimental load-displacement relationships in the Section "Results and Discussions".

$$
\begin{gathered}
\delta_{\mathrm{y}}=\sum_{i=1}^{5} \chi_{i} \cdot l_{i} \cdot h_{i} \\
\delta_{\mathrm{p}}=\chi_{\mathrm{p}} \cdot l_{\mathrm{p}} \cdot\left(H-\frac{l_{\mathrm{p}}}{2}\right) \\
\delta_{\mathrm{t}}=\delta_{\mathrm{y}}+\delta_{\mathrm{p}}
\end{gathered}
$$




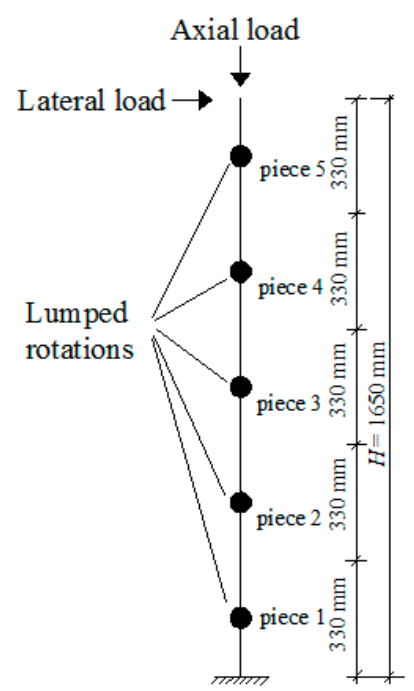

Figure 10. The locations of lumped rotations.

\subsection{Shear Strength before and after Retrofit}

According to ACI 318M-14 [69], before retrofit, the shear strength, which includes contributions of concrete and transverse reinforcement, can be obtained using Equations (5) and (6). In these equations, $V_{\mathrm{s}}$ is the nominal shear strength provided by transverse reinforcement, $A_{\mathrm{V}}$ is the area of the transverse reinforcement, $f_{\mathrm{yt}}$ is the design yield strength of transverse reinforcement, $d$ is the effective depth, $s$ is the spacing of shear reinforcement, $V_{\mathrm{c}}$ is the nominal shear strength provided by concrete, $N_{\mathrm{u}}$ is the factored axial load normal to cross-section (to be taken as positive for compression), $A_{\mathrm{g}}$ is the gross area of the column section, $f^{\prime}{ }_{\mathrm{c}}$ is the design compressive strength of concrete, $b_{\mathrm{w}}$ is the width of the column,

$$
\begin{gathered}
V_{\mathrm{s}}=\frac{A_{\mathrm{v}} f_{\mathrm{yt}} d}{\mathrm{~s}} \\
V_{\mathrm{c}}=0.166\left(1+\frac{N_{\mathrm{u}}}{14 A_{\mathrm{g}}}\right) \cdot \sqrt{f{ }_{\mathrm{c}}} b_{\mathrm{w}} d
\end{gathered}
$$

According to ACI-440-2R-08 [5], the contribution of FRP reinforcement to shear strength can be obtained using Equations (7) and (8).

$$
\begin{gathered}
V_{\mathrm{f}}=\frac{A_{\mathrm{fv}} \cdot \varepsilon_{\mathrm{fe}} \cdot E_{\mathrm{f}} \cdot d_{\mathrm{fv}}}{s_{\mathrm{f}}} \\
A_{\mathrm{fv}}=2 n \cdot t_{\mathrm{f}} \cdot w_{\mathrm{f}}
\end{gathered}
$$

where $V_{\mathrm{f}}$ is the FRP contribution to shear strength, $A_{\mathrm{fv}}$ is the area of FRP shear reinforcement, $\varepsilon_{\mathrm{fe}}$ is the effective strain of FRP sheet attained at failure, which was assumed to be 0.004 as recommended by ACI-440-2R-08 [5] and TSDC [57], $E_{\mathrm{f}}$ is the tensile modulus of elasticity of FRP shear reinforcement, $d_{\mathrm{fv}}$ is the effective depth of FRP shear reinforcement, $s_{\mathrm{f}}$ is the spacing of FRP reinforcement plies, $n$ is the number of plies of FRP reinforcement, $t_{\mathrm{f}}$ is nominal thickness of one ply of FRP reinforcement, and $w_{\mathrm{f}}$ is the width of FRP reinforcement plies.

According to ACI-440-2R-08 [5], the total shear strength of the cross-section $\left(V_{\mathrm{n}}\right)$ resisted with FRP reinforcement, concrete and transverse reinforcement can be obtained using Equation (9).

$$
V_{\mathrm{n}}=V_{\mathrm{c}}+V_{\mathrm{s}}+\psi_{\mathrm{f}} V_{\mathrm{f}}
$$

where $\psi_{\mathrm{f}}$ is the FRP strength reduction factor and was assumed to be 0.95 as recommended by ACI-440-2R-08 [5] for shear fully wrapped sections. 
Since the shear strengths of the columns (before and after retrofit) were remarkably higher than their flexural strengths, as expected, flexural effects dominated the behavior of the specimens (Table 3). This table includes the observed and predicted failure modes, which are consistent.

Table 3. Theoretical and experimental lateral load capacities and consecutive failure modes of the columns.

\begin{tabular}{|c|c|c|c|}
\hline Specimens & REF & LAM and LAM-PB & LAM-LAM \\
\hline Theoretical lateral load capacity $(\mathrm{kN})$ & 21.2 & 32.1 & 41.8 \\
\hline Experimental lateral load capacity $(\mathrm{kN})$ & 24.5 & $\begin{array}{c}33.8 \text { (for the specimen } \\
\text { LAM) } 34.6 \text { (for the } \\
\text { specimen LAM-PB) }\end{array}$ & 45.1 \\
\hline Theoretical moment capacity $\left(M_{0}\right)(\mathrm{kNm})$ & 36.5 & 55.0 & 72.4 \\
\hline Theoretical failure mode & Y before C & $\mathrm{Y}, \mathrm{T}$ & $\mathrm{Y}$, then $\mathrm{T}$ \\
\hline Observed failure mode & Y before C & $\mathrm{Y}, \mathrm{F}$ & $\mathrm{Y}, \mathrm{FA}$ \\
\hline Shear strength $(\mathrm{kN})$ & $108.0\left(V_{\mathrm{c}+} V_{\mathrm{s}}\right)$ & \multicolumn{2}{|c|}{$260.6\left(V_{\mathrm{c}+} V_{\mathrm{s}+} \psi_{f} \cdot V_{\mathrm{f}}\right)$} \\
\hline
\end{tabular}

Y: Tensile reinforcement yields; C: Concrete crushes; T: AFRP reinforcement reaches its ultimate tensile capacity; F: AFRP reinforcement fractured; FA: Both AFRP reinforcement and anchorage fractured.

\subsection{Anchorage Length for FRP Reinforcement in Footing}

In order to utilize the full capacity of the FRP reinforcement, the failure of FRP reinforcement was desired to be due to rupture of the reinforcement rather than pullout, concrete splitting, concrete cone and spacing and edge cone failures, which have been listed as five primary failure modes in ACI-355-1R-91 [70]. Among these failures, the possibility of concrete cone, concrete splitting and edge cone failures was significantly reduced due to the constraining effect of steel reinforcing bars in the footing, where the conical anchor holes were dug in. Therefore, only possibilities of pullout failure and fracture of FRP reinforcement were taken into account by comparing the tensile strength of FRP reinforcement and the adhesion between concrete and epoxy grout (Equations (10) and (11)). In these equations, $F_{\text {bond }}$ is the bond capacity, $\tau_{b}$ is the uniform bond strength along the anchorage length, $l_{\mathrm{db}}$ is the embedment length, while $u$ is the perimeter, $F_{\text {frp }}$ is the tensile capacity of the FRP reinforcement, $\varepsilon_{\mathrm{fu}}$ is the design rupture strain of FRP reinforcement, and $A_{\mathrm{frp}}$ is the cross-sectional area of the FRP reinforcement. For the selected embedment length $(300 \mathrm{~mm})$, the calculated value of $F_{\text {bond }}(1012 \mathrm{kN})$ was far over $F_{\text {frp }}(277 \mathrm{kN})$, which clearly eliminated the possibility of pullout failure. It should be noted that while calculating $F_{\mathrm{bond}}, \tau_{\mathrm{b}}$ was calculated to be $6.3 \mathrm{~N} / \mathrm{mm}^{2}$ based on ACI-355-1R-91 [70]. Moreover, test results of the retrofitted columns also confirmed that the embedment length of FRP reinforcement was sufficient. No debonding problem or damages resulting from concrete cone, concrete splitting, edge cone and pullout failures were observed during the tests.

$$
\begin{gathered}
F_{\text {bond }}=\tau_{\mathrm{b}} \cdot l_{\mathrm{db}} \cdot u \\
F_{\text {frp }}=E_{\mathrm{f}} \cdot \varepsilon_{\mathrm{fu}} \cdot A_{\mathrm{frp}}
\end{gathered}
$$

\section{Results and Discussions}

The test results were outlined through hysteretic load-displacement curves, envelopes of these curves, strain distributions along longitudinal, transverse steel and longitudinal AFRP reinforcement, energy dissipation capacities, average section rotations in different gauge lengths and damage progression and distribution. Furthermore, experimental data was compared with the theoretical findings. 


\subsection{Lateral Load-Displacement Curves and Failure Modes}

The hysteretic lateral load-displacement curves and their envelopes are presented in Figures 11 and 12 respectively. The damage progression of the columns with increasing drifts is summarized in Table 4.


Figure 11. Experimental and theoretical lateral load-displacement curves for all specimens (rein., reinforcement).

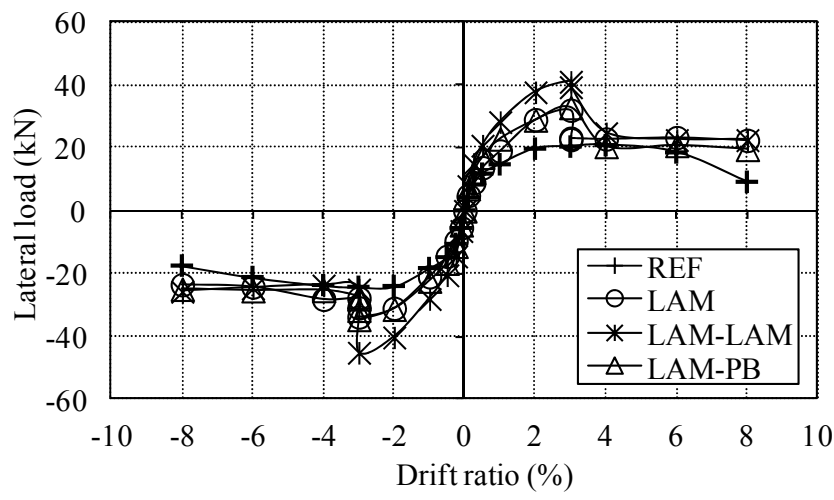

Figure 12. The envelopes of load-displacement relationships. 
Table 4. Damage progression of the columns (The numbers are drift ratios in \%).

\begin{tabular}{ccccc}
\hline \multirow{2}{*}{ Damage mechanisms } & \multicolumn{5}{c}{ Specimens } \\
\cline { 2 - 5 } & REF & LAM & LAM-LAM & LAM-PB \\
\hline Yielding of longitudinal steel bars & 2 & 3 & 3 & 3 \\
\hline Crushing of concrete cover & 3 & - & - & - \\
\hline Spalling of concrete cover & -6 & - & - & - \\
\hline Fracture of AFRP reinforcement & - & 3 & 3 & 3 \\
\hline
\end{tabular}

As seen in Figures 11 and 12 and Table 3, the reference column (REF) reached its theoretical flexural capacity and exhibited a ductile behavior. The column LAM, retrofitted with AFRP reinforcement, experienced an enhancement in strength up to the drift ratio around 3\%. At this drift, the enhancement in strength was around 38\% with respect to the column REF. The sudden remarkable loss of strength upon exceeding the drift ratio around $3 \%$ was due to the fracture of AFRP reinforcement at the interface of the column and the footing (Figure 13a). As seen in Figures 11 and 12 the column LAM-LAM exhibited a remarkably superior performance with respect to the reference and the other retrofitted columns by resisting lateral loads, approximately 1.9 and 1.3 times the loads resisted by the reference and other retrofitted columns, respectively. As seen in Figure 11, the column LAM-LAM also sustained its lateral load capacity until the drift ratio of $3 \%$, around where the AFRP reinforcement and AFRP anchorage reinforcement fractured at the same section (Figure 13b). The higher strength of the column LAM-LAM is due to the contribution of additional AFRP anchorage reinforcement to the flexural capacity. The column LAM-PB behaved similar to the column LAM in terms of maximum lateral load and fracture of AFRP reinforcement around 3\% drift ratio. At this drift ratio, the enhancement in strength was around $41 \%$ with respect to the column REF. It was observed that, while pulling, both AFRP reinforcements under tension were fractured upon exceeding the drift ratio of $3 \%$. On the other hand, while pushing, only one AFRP reinforcement under tension fractured, whereas the other one did not fracture, instead, decomposed locally just above the isolated height (Figure 13c). Decomposition is the separation of the individual fibers after fracture of the epoxy matrix. Contribution of decomposed AFRP reinforcement to the behavior at larger drifts limited plastic residual deformations of the column LAM-PB. As seen in Figure 11, marginal residual displacements remained after unloading branches in pulling direction up to $8 \%$ drift ratio. Therefore, this type of anchorage system can be used to limit the residual displacement (and consequently residual damage). The retrofitted columns behaved similar in terms of strength degradation after the rupture of FRP reinforcement as the specimens tested by Ilki and Kumbasar [46], Bournas and Triantafillou [47], and Vrettos et al. [50], where the drift ratios at failure were approximately $2 \%, 4 \%$ and $2.5 \%$, respectively. It is important to note that all significant damage was accumulated at the base of the columns, since the columns were wrapped with CFRP sheets in transverse direction along the full height. Consequently, the crack width reached several centimeters at the intersection of the column and the footing. This type of damage may be quite disadvantageous in case of earthquakes since the distribution of plastic deformations through the potential plastic hinge length is prevented due to presence of a rigid transverse CFRP jacket. The accumulation of a remarkable portion of plastic deformations only at the interface of the column and the footing may significantly reduce the overall drift capacity of the column. Since drift capacity is essentially important for a satisfactory seismic performance, this kind of reduction in drift capacity should be avoided. This problem can be overcome by application of transverse sheets in strips allowing distribution of damage (and plastic deformations) in the unconfined zones between transverse FRP strips. 

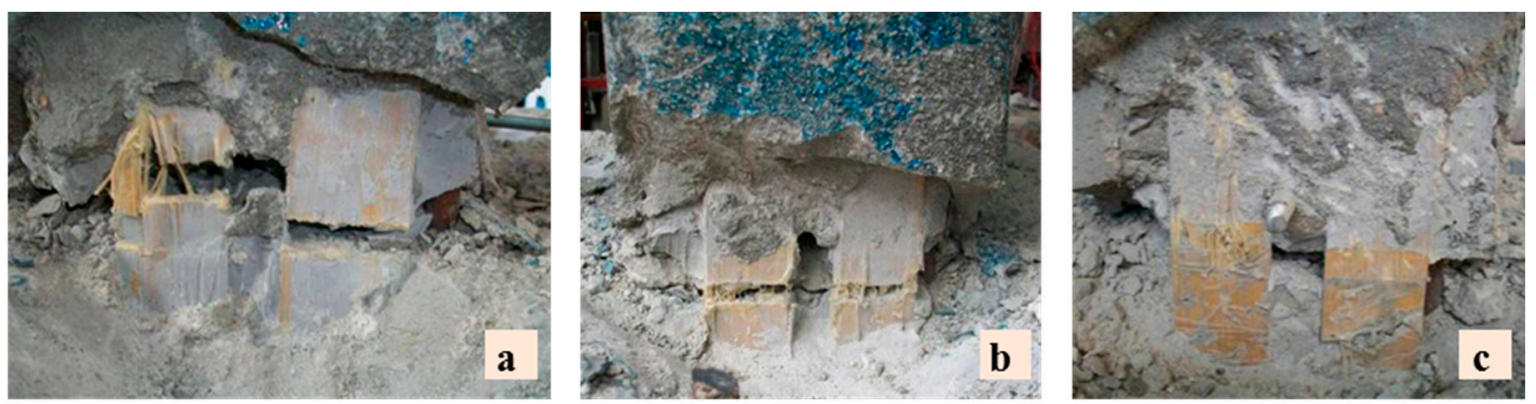

Figure 13. Fracture of AFRP reinforcement during the test (a) the column LAM at $3 \%$ drift ratio, (b) the column LAM-LAM at 3\% drift ratio, and (c) the column LAM-PB at 3\% drift ratio.

Average experimental moment-curvature relationships obtained for critical sections of columns are presented in Figure 14. In this figure $M$ (Second order effect is considered) is the experimental moment, $M_{0}$ is the theoretical moment capacity calculated per specimen, which is obtained by fiber analysis approach. The theoretical moment capacities $\left(M_{0}\right)$ are presented in Table 3. For the calculation of experimental moment-curvature relationships, the average curvature values obtained along 0-20 mm, 20-150 mm, and 150-300 $\mathrm{mm}$ heights above the footing were taken into account. As seen in Figure 14, for the retrofitted columns, the average curvature values of the column sections measured along 0-20 mm height were in the order of $4.5 \times 10^{-3}(1 / \mathrm{mm})$, while the curvatures measured in 20-150 mm height above the footing were in the order of $4.5 \times 10^{-4}(1 / \mathrm{mm})$. Since the curvature values of the columns measured along 150-300 mm height were even smaller, these results are not presented in Figure 14. In agreement with these measurements, the damage was also accumulated particularly in $20 \mathrm{~mm}$ height of the column from top of the footing. During the autopsy after the tests, no concrete crushing and no cracking (other than the main crack at the interface of the column and the footing) were observed on the retrofitted columns. On the other hand, the deformations (as well as cracks) were distributed through the column height in case of the reference column.

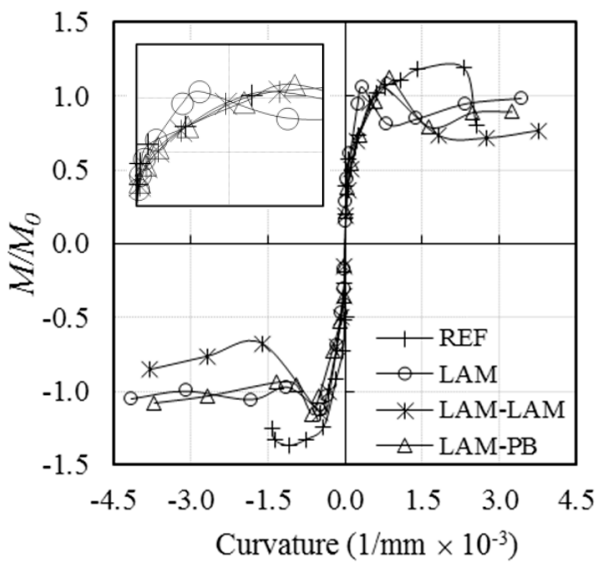

(a)

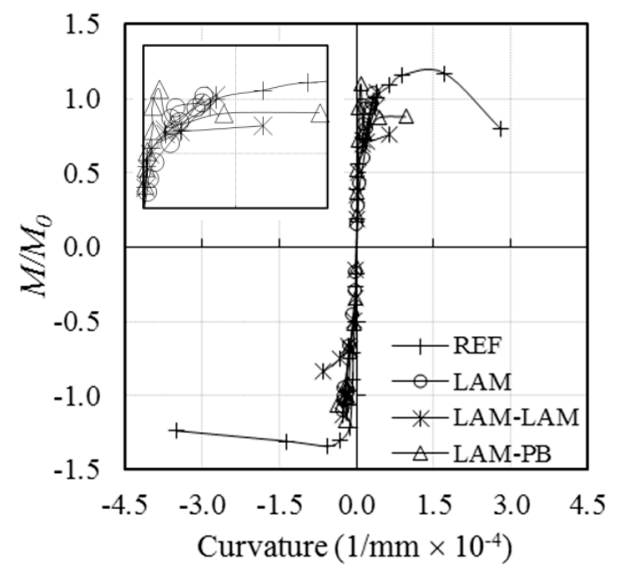

(b)

Figure 14. Moment-curvature relationships obtained in columns (a) 0-20 mm, and (b) 20-150 mm above the footing. (The 0.0-1.0 region of the figure is blown up at the left hand side of the figure).

\subsection{Strains of Steel and AFRP Reinforcement}

The strain values were obtained by making use of the strain gauges on longitudinal and transverse steel, and longitudinal AFRP reinforcement (Figure 15). The efficiency of AFRP reinforcement on flexural capacity can also be seen through the measured strains of longitudinal 
AFRP reinforcement. The maximum strains of longitudinal AFRP reinforcements in tension were measured to be in the range of 0.01 right before the rupture of the AFRP reinforcement. This value corresponded to approximately $43 \%$ of design rupture strain of FRP reinforcement. ACI 440-2R-08 [5] recommends to reduce $\varepsilon_{\mathrm{fu}}$ by using a factor of 0.70 for NSM application technique under monotonic flexural loading. This value is quite unconservative for the applied retrofitting technique in this study. It shall be much lower for cyclic loading based on the test results. In the study of Vrettos et al. [50], where the longitudinal CFRP sheets together with CFRP anchors were used for flexural retrofitting of RC columns, the measured strains were also far behind (approximately $38 \%$ of design rupture strain of FRP reinforcement) the strain reduction factor recommended by ACI 440-2R-08 [5]. It should be noted that, in the study of Vrettos et al. [50], the ultimate rupture strain of FRP reinforcement was not measured directly through pre-installed strain gauges but calculated through analysis of the cross-section at the column base by using conventional RC force equilibrium, strain compatibility, and material constitutive relationships based on the test results. As shown in Figure 15c,f, right after the rupture of the AFRP reinforcement, the strains decrease within the AFRP reinforcement, and corresponding stresses are transferred to the longitudinal reinforcing bars (the strains of steel bars increased remarkably along the measured height). The longitudinal steel bars of the column REF yielded at drift ratio of $2 \%$, while that of retrofitted columns yielded at drift ratio around $3 \%$ right after the columns experienced strength degradation due to rupture of AFRP reinforcement. Since steel reinforcing bars in tension already reached their yield strain at around $3 \%$ drift ratio before rupture of AFRP reinforcement, the brittle failure of the column was avoided. It should be noted that drift ratios exceeding 3\% may only be expected if substandard RC structures are subjected to severe earthquakes. Nevertheless, after AFRP reinforcements were fractured at around 3\% drift ratio, the columns still resisted considerable lateral forces due to contribution of steel reinforcing bars until extremely large drift ratios $(\sim 6 \%$ to $8 \%)$ and kept their vertical load resisting capacities. According to strain gauge measurements, strains of longitudinal steel bars did not reach tensile strain corresponding to strain hardening. This observation is consistent with the nearly horizontal branch of the load-displacement relationships after fracture of AFRP reinforcement. On the other hand, none of the stirrups yielded (strains are in the range of 0.00004 and 0.0006) and no damage was observed on CFRP sheets in transverse direction due to relatively low level of applied axial load $(20 \%$ axial load capacity of the column) and shear stresses.

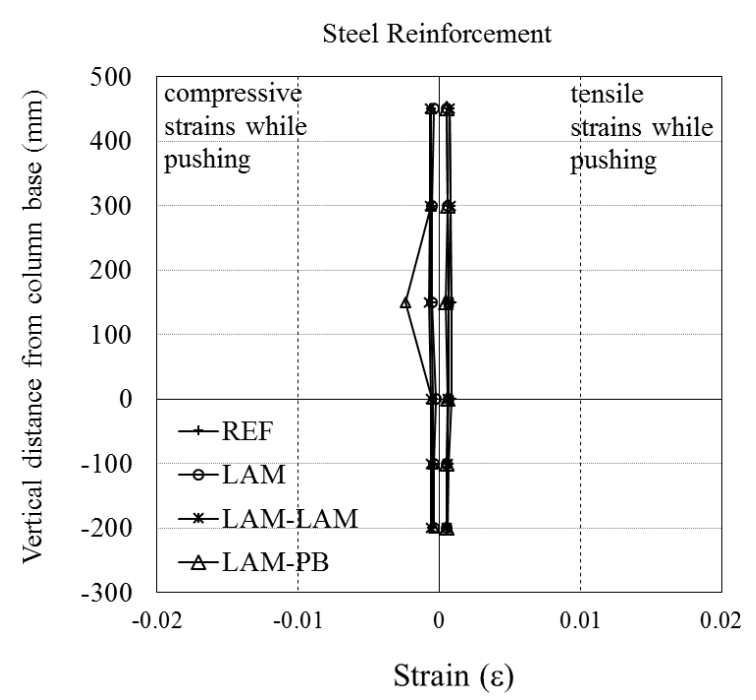

(a)

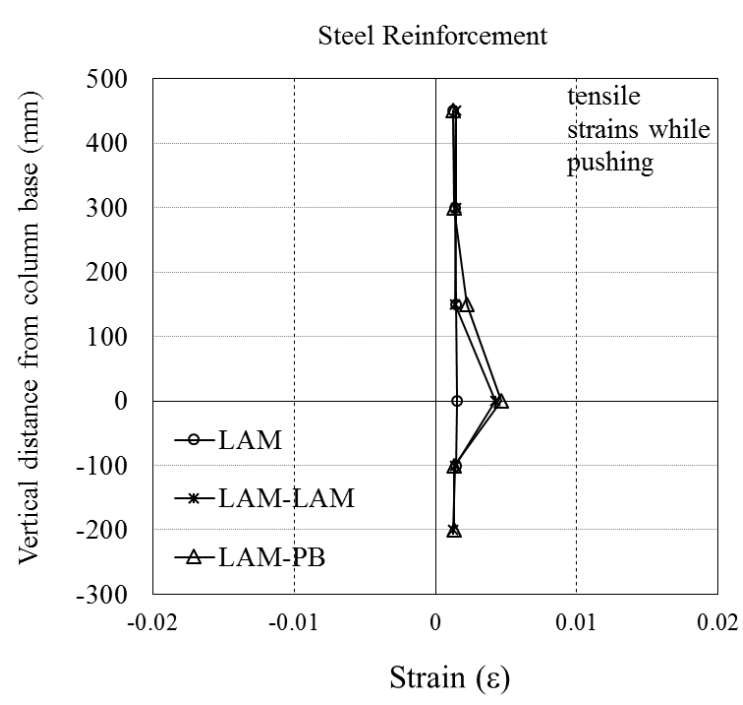

(b)

Figure 15. Cont. 


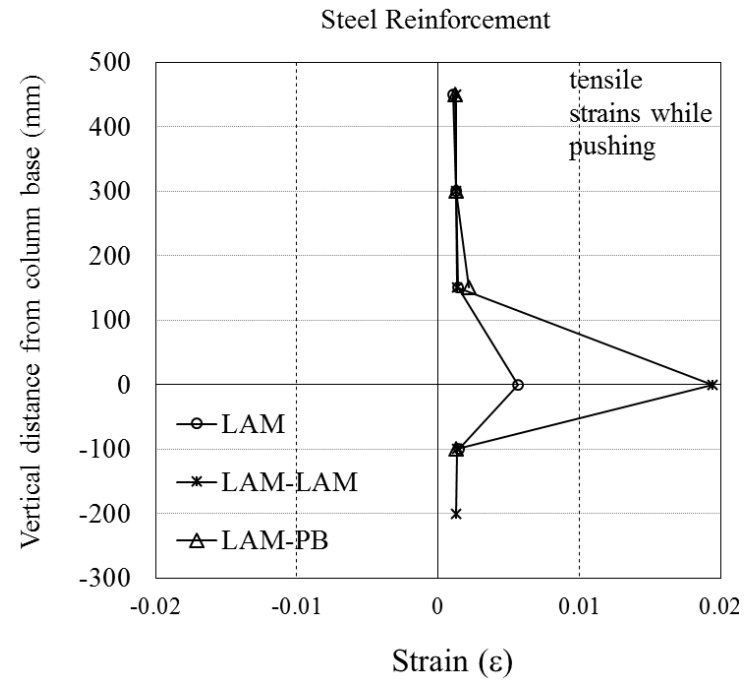

(c)

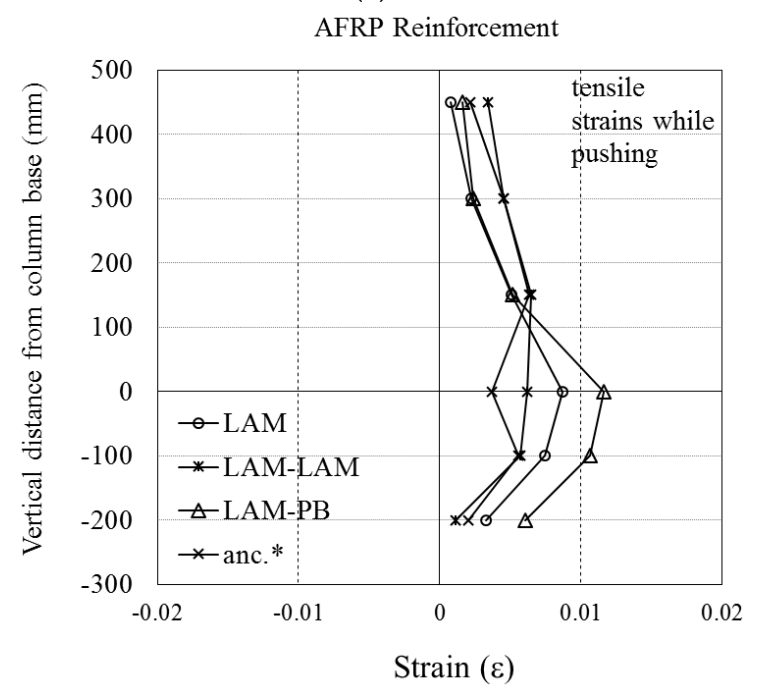

(e)

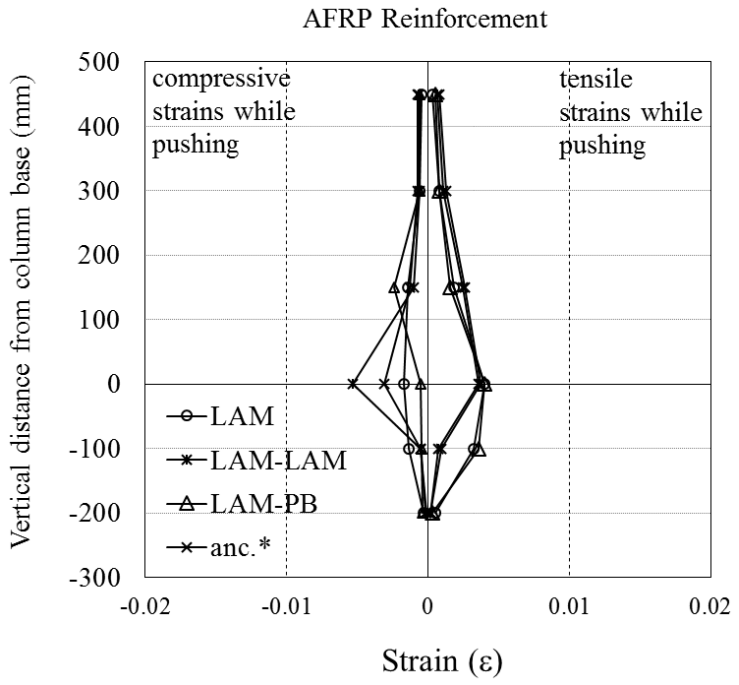

(d)

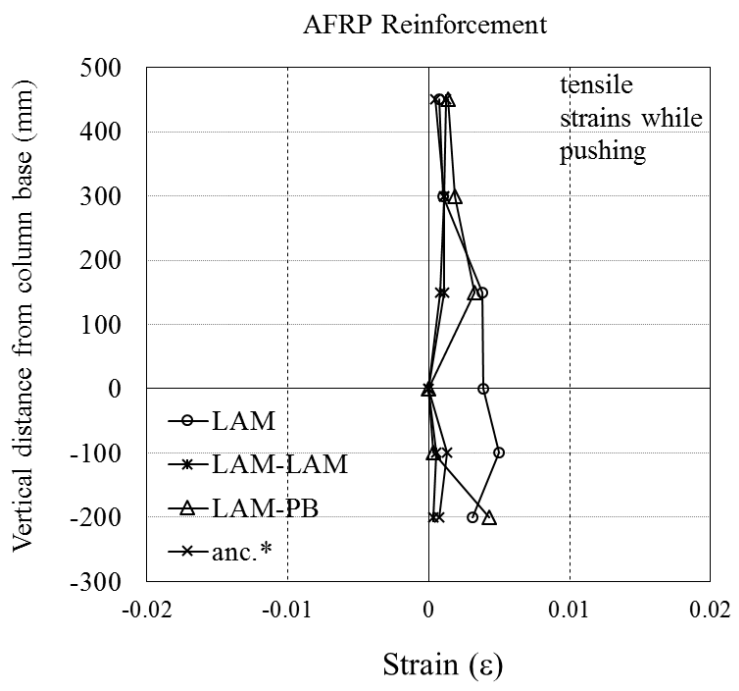

(f)

Figure 15. Strain distribution of longitudinal steel reinforcement (a) at \pm 0.01 drift ratio, (b) right before rupture of AFRP reinforcement (at around 3\% drift ratio), (c) right after rupture of AFRP reinforcement (at around 3\% drift ratio), and AFRP reinforcement (d) at \pm 0.01 drift ratio, (e) right before rupture of AFRP reinforcement (at around 3\% drift ratio), (f) right after rupture of AFRP reinforcement (at around 3\% drift ratio). * strain measurements obtained from additional AFRP anchorage reinforcements for the column LAM-LAM.

\subsection{Energy Dissipation Capacities}

Energy dissipation capacities of the tested columns are calculated as the areas enclosed by the load-displacement hysteresis loops and presented in Figure 16. As seen in this figure, until the rupture of the AFRP reinforcement, the column LAM-LAM shows the highest energy dissipation capacity due to its higher lateral load capacity with respect to other columns. Moreover, the energy dissipation capacity of the column LAM is higher than the column LAM-PB. This is due to larger elastic deformations along the embedded unbonded length of AFRP reinforcement in case of column LAM-PB. After the rupture of the AFRP reinforcement, energy dissipation capacities of the columns LAM and LAM-LAM are approximately same, since the columns behave like the reference column in terms of sustained lateral load. As seen in Figure 16, the dissipated energy is significantly 
less for column LAM-PB due to elastic behavior of unbonded AFRP reinforcement. Nevertheless, with the gradual damaging of AFRP reinforcement, the contribution of AFRP reinforcement to the elastic behavior is diminished and plastic deformations increased causing more significant residual displacements with respect to previous loading cycles.

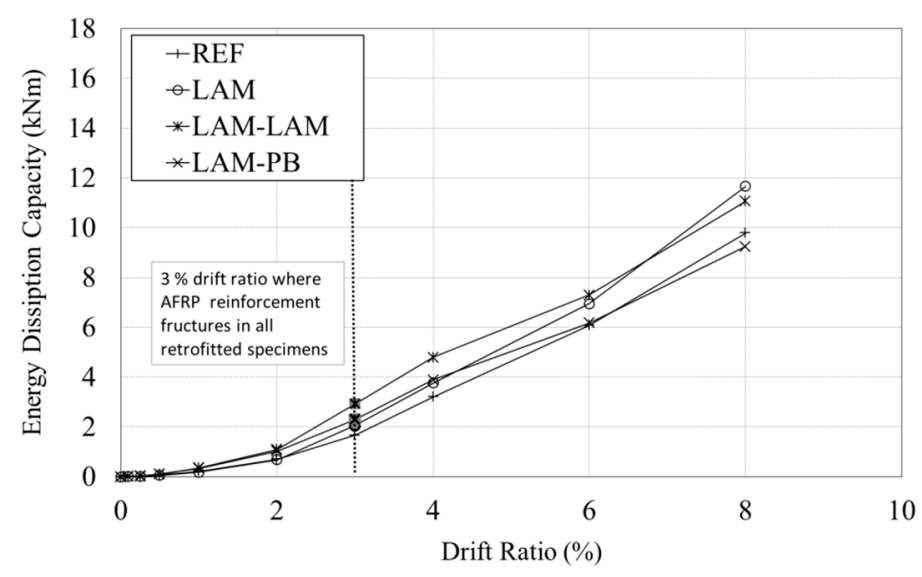

Figure 16. Energy dissipation capacities of the columns.

\section{Conclusions}

In this study, the effects of using anchored and embedded AFRP laminate longitudinal reinforcement for the flexural retrofit of substandard RC columns were investigated. The tests were conducted under constant axial load and reversed cyclic lateral loads. Based on the experimental and theoretical studies, the following conclusions/observations can be listed:

- The reference column reached its theoretical flexural capacity, and exhibited a ductile behavior as foreseen during design.

- The retrofitted columns (LAM, LAM-LAM, LAM-PB) failed due to the rupture of AFRP reinforcement at around 3\% drift ratio. At this drift ratio, the enhancement in strength was around $38 \%, 90 \%$ and $41 \%$ for the columns LAM, LAM-LAM, and LAM-PB, respectively, with respect to the reference column. It should be noted that drift ratios exceeding $3 \%$ may only be expected if substandard RC structures are subjected to severe earthquakes. Nevertheless, after AFRP reinforcements were fractured at around 3\% drift ratio, the columns still resisted considerable lateral forces due to contribution of steel reinforcing bars until extremely large drift ratios $(\sim 6 \%$ to $8 \%)$. The column LAM-LAM exhibited a remarkably superior performance with respect to the reference and the other retrofitted columns due to additional AFRP anchorage reinforcement. When compared with the column LAM, the proposed anchorage type used for the column LAM-PB, limited the residual plastic deformations, while did not affect the lateral load capacity adversely. Therefore, this type of anchorage system can be utilized to limit the residual displacement and corresponding damage. It was observed that the predicted results through theoretical calculations satisfactorily captured the tested results by means of lateral load and deformation capacities, particularly, when $43 \%$ of the design rupture strain of FRP reinforcement was considered as the rupture strain of the FRP reinforcement during theoretical calculations.

- The AFRP reinforcement of the retrofitted columns ruptured at the interface of the column and the footing. The experimentally measured rupture strain of AFRP reinforcement was observed to be approximately $43 \%$ of design rupture strain of FRP reinforcement. Therefore, the strain reduction factor $(70 \%)$ recommended by ACI 440-2R-08 [5] for NSM applications under monotonic loading conditions may lead to unconservative predictions of lateral load-deformation capacity for the proposed retrofitting technique in this study under cyclic loading conditions. Clearly, further 
investigations are also needed to accurately identify the theoretical seismic behavior of the columns retrofitted using NSM techniques under cyclic loading conditions.

It can be inferred from the results of this study that the proposed retrofitting method is promising for improving the seismic performance of substandard columns built with low quality concrete under reversed cyclic flexure and axial force. It should be noted that these conclusions are mainly based on the test results of this study, therefore, they are limited to the ranges of test parameters and details considered in this study.

Acknowledgments: The financial support of the ITU Scientific Research Department (Scientific Research Project No:326024), BASF and ART-YOL Companies and the assistance of staff of Structural and Earthquake Engineering Laboratory and Building Materials Laboratory of Istanbul Technical University are acknowledged gratefully.

Author Contributions: Alper Ilki coordinated the study. Ahmet Uzunhasanoglu worked on production of the specimens. All authors contributed to the execution of the tests. Engin C. Seyhan and Caglar Goksu contributed to the processing of the test data. The paper was written by Engin C. Seyhan, Caglar Goksu and Alper Ilki.

Conflicts of Interest: The authors declare no conflict of interest.

\section{Notations}

AFRP Aramid fiber reinforced polymer

$A_{\text {frp }} \quad$ Cross-section area of the FRP anchor reinforcement

$A_{\mathrm{fv}} \quad$ Area of FRP shear reinforcement

$A_{\mathrm{g}} \quad$ Gross area of the column section

$A_{\mathrm{u}} \quad$ Cross-sectional area of the transverse reinforcing bar

$b_{\mathrm{w}} \quad$ Web width of the column

$C_{\mathrm{E}} \quad$ Environmental reduction factor according to ACI 440-2R-08 2008

CFRP Carbon fiber reinforced polymer

$d \quad$ Distance from extreme compression fiber through centroid of tension steel reinforcement

$d_{\mathrm{fv}} \quad$ Effective depth of FRP shear reinforcement

$E_{f} \quad$ Tensile elastic modulus of FRP reinforcement

$f_{c}^{\prime} \quad$ Design compressive strength of concrete

$f_{\max } \quad$ Tensile strength of longitudinal and transverse reinforcing bar

$f_{y} \quad$ Yield stress of longitudinal reinforcing bar

$f_{\text {yt }} \quad$ Design yield strength of transverse reinforcement

$F_{\text {bond }} \quad$ Bond capacity of epoxy grout on AFRP reinforcement

$F_{\text {frp }} \quad$ Tensile strength of FRP

FRP Fiber reinforced polymer

GFRP Glass fiber reinforced polymer

$H \quad$ Distance between the interface of the column and the footing and the point of application of the lateral load

$h_{\mathrm{i}} \quad$ Distance between the center of the respective part and the tip of the column, where the lateral load is applied

$l_{\mathrm{db}} \quad$ Embedment length

$l_{i} \quad$ Length of the respective part of the column

$l_{\mathrm{p}} \quad$ plastic hinge length

$M \quad$ Experimental moment capacity

$M_{0} \quad$ Theoretical moment capacity calculated by fiber analysis approach

$n \quad$ Number of plies of FRP sheet

NSM Near surface mounted

$N_{u} \quad$ Factored axial load normal to cross-section (to be taken as positive for compression)

RC Reinforced Concrete

$s \quad$ Spacing of shear reinforcement measured in a direction parallel to the longitudinal reinforcement

$s_{\mathrm{f}} \quad$ Spacing of FRP reinforcement plies

$t_{\mathrm{f}} \quad$ Nominal thickness of one ply of FRP reinforcement

$u \quad$ Perimeter of the FRP anchor

$V_{\mathrm{c}} \quad$ Nominal shear strength provided by concrete 
$V_{\mathrm{S}} \quad$ Nominal shear strength provided by shear reinforcement

$V_{\mathrm{n}} \quad$ Nominal shear strength

$V_{r-f r p} \quad$ Nominal shear strength (with the contribution of FRP)

$V_{\mathrm{f}} \quad$ FRP contribution to shear strength

$w_{\mathrm{f}} \quad$ Effective width of FRP reinforcement

$\delta_{\mathrm{t}} \quad$ Top displacement of the column

$\theta_{\mathrm{p}} \quad$ Plastic rotation

$\varepsilon_{\mathrm{c} 0} \quad$ Axial strain corresponding to unconfined concrete strength

$\varepsilon_{\mathrm{cc}} \quad$ Axial strain corresponding to confined concrete strength

$\varepsilon_{\mathrm{fe}} \quad$ Effective strain of FRP sheet attained at failure

$\varepsilon_{f u} \quad$ Design rupture strain of FRP reinforcement

$\varepsilon_{f u}{ }^{*} \quad$ Ultimate rupture strain of FRP reinforcement declared by manufacturer

$\rho_{\mathrm{s}} \quad$ Existing volumetric ratio of transverse reinforcement of columns

$\rho_{\mathrm{sm}} \quad$ Required volumetric ratio of transverse reinforcement of columns

$\tau_{\mathrm{b}} \quad$ Uniform bond strength along the anchorage length

$\chi_{\mathrm{i}} \quad$ Curvature of the respective part of the column

$\chi_{p} \quad$ Curvature of the plastic part of the column

$\psi_{\mathrm{f}} \quad$ FRP strength reduction factor

\section{References}

1. CEB-FIB. Externally Bonded FRP Reinforcement for RC Structures; Technical report for International Federation for Structural Concrete: Lausanne, Switzerland, 2001.

2. Pessiki, S.; Harries, K.A.; Kestner, J.T.; Sause, R.; Ricles, J.M. Axial behavior of reinforced concrete columns confined with FRP jackets. J. Compos. Constr. 2001, 5, 237-245. [CrossRef]

3. Bakis, C.E.; Bank, L.C.; Brown, V.L.; Cosenza, E.; Davalos, J.F.; Lesko, J.J.; Machida, A.; Rizkalla, S.H.; Triantafillou, T.C. Fiber-reinforced polymer composites for construction-State-of-the-Art Review. J. Compos. Constr. 2002, 6, 73-87. [CrossRef]

4. Lam, L.; Teng, J.G. Design-oriented stress-strain model for FRP-confined concrete. Constr. Build. Mater. 2003, 17, 471-489. [CrossRef]

5. ACI 440.2R-08. Guide for design and construction of externally bonded FRP systems for strengthening concrete structures. American Concrete Institute 440: Farmington Hills, MI, USA, 2008.

6. Bank, L.C. Progressive failure and ductility of FRP composites for construction: Review. J. Compos. Constr. 2013, 17, 406-419. [CrossRef]

7. Bennitz, A.; Schmidth, J.W.; Nilimaa, J.; Taljsten, B.; Goltermann, P.; Ravn, D.L. Reinforced concrete T-beams externally prestressed with unbonded carbon fiber-reinforced polymer tendons. Struct. J. 2012, 109, $521-530$.

8. Lou, T.; Lopes, S.M.R.; Lopes, A. Numerical analysis of behaviour of concrete beams with external FRP tendons. Constr. Build. Mater. 2012, 35, 970-978. [CrossRef]

9. Lou, T.; Lopes, S.M.R.; Lopes, A. External CFRP tendon members: Secondary reactions and moment redistribution. Compos. Eng. 2014, 57, 250-261. [CrossRef]

10. Seible, F.; Priestley, M.J.; Hegemier, G.A.; Innamorato, D. Seismic retrofit of RC columns with continuous carbon fiber jackets. J. Compos. Constr. 1997, 1, 52-62. [CrossRef]

11. Sheikh, S.; Yau, G. Seismic behavior of concrete columns confined with steel and fiber-reinforced polymers. Struct. J. 2002, 99, 72-80.

12. Antonopoulos, C.P.; Triantafillou, T.C. Experimental investigation of FRP-strengthened RC beam-column joints. J. Compos. Constr. 2003, 7, 39-49. [CrossRef]

13. Iacobucci, R.D.; Sheikh, A.S.; Bayrak, O. Retrofit of square concrete columns with carbon fiber-reinforced polymer for seismic resistance. Struct. J. 2003, 100, 785-794.

14. Xiao, Y. Applications of FRP composites in concrete columns. Adv. Struct. Eng. 2004, 7, 335-343. [CrossRef]

15. Prota, A.; Nanni, A.; Manfredi, G.; Cosenza, E. Selective upgrade of underdesigned reinforced concrete beam-column joints using carbon fiber polymers. Struct. J. 2004, 101, 699-707.

16. Bousias, S.N.; Triantafillou, T.C.; Fardis, M.N.; Spathis, L.; O'Regan, B.A. Fiber-reinforced polymer retrofitting of rectangular reinforced concrete columns with or without corrosion. Struct. J. 2004, 101, $512-520$. 
17. Chang, S.; Li, Y.; Loh, C. Experimental study of seismic behaviors of as-built and carbon fiber reinforced plastics repaired reinforced concrete bridge columns. J. Bridge Eng. 2004, 9, 391-402. [CrossRef]

18. Memon, M.S.; Sheikh, S.A. Seismic resistance of square concrete columns retrofitted with glass fiber-reinforced polymer. Struct. J. 2005, 102, 774-783.

19. Tsonos, A.G. Effectiveness of CFRP-jackets in post-earthquake and pre-earthquake retrofitting of beam-column subassemblages. Struct. Eng. Mech. 2007, 27, 393-408. [CrossRef]

20. Ilki, A.; Demir, C.; Bedirhanoglu, I.; Kumbasar, N. Seismic retrofit of brittle and low-strength RC columns using fiber reinforced polymer and cementitious composites. Adv. Struct. Eng. 2009, 12, 325-347. [CrossRef]

21. Garcia, R.; Hajirasouliha, I.; Pilakoutas, K. Seismic behaviour of deficient RC frames strengthened with CFRP composites. Eng. Struct. 2010, 32, 3075-3085. [CrossRef]

22. Ilki, A.; Bedirhanoglu, I.; Kumbasar, N. Behavior of FRP retrofitted joints built with plain bars and low-strength concrete. J. Compos. Constr. 2011, 15, 312-326. [CrossRef]

23. Wang, Z.; Wang, D.; Smith, S.T.; Lu, D. CFRP-confined square RC columns. I: Experimental investigation. J. Compos. Constr. 2011, 16, 150-160. [CrossRef]

24. Jirawattanasomkul, T.; Zhang, D.W.; Ueda, T. Prediction of the post-peak behavior of reinforced concrete columns with and without FRP-jacketing. Eng. Struct. 2013, 56, 1511-1526. [CrossRef]

25. Parvin, A.; Brighton, D. FRP composites strengthening of concrete columns under various loading conditions. Polymers 2014, 6, 1040-1056. [CrossRef]

26. Demir, C.; Darılmaz, K.; Ilki, A. Cyclic stress-strain relationships of FRP confined concrete members. Arabian J. Sci. Eng. 2015, 40, 363-379. [CrossRef]

27. Nanni, A.; Alkhrdaji, T.; Chen, G.; Barker, M.; Yang, X.; Mayo, R. Overview of testing to failure program of a highway bridge strengthened with FRP composites. In Proceedings of Fourth International Symposium on FRP for Reinforcement of Concrete Structures, Baltimore, MD, USA, November 1999; pp. 69-80.

28. De Lorenzis, L.; Nanni, A. Bond between near surface mounted fiber reinforced polymer rods and concrete in structural strengthening. Struct. J. 2002, 99, 123-132.

29. De Lorenzis, L.; Lundgren, K.; Rizzo, A. Anchorage length of near-surface mounted fiber reinforced polymer bars for concrete strengthening-experimental investigation and numerical modelling. Struct. J. 2004, 101, 269-278.

30. Hassan, T.K.; Rizkalla, S.H. Bond mechanism of near-surface-mounted fiber-reinforced polymer bars for flexural strengthening of concrete structures. Struct. J. 2004, 101, 830-839.

31. El-Hacha, R.; Rizkalla, S.H. Near-surface-mounted fiber-reinforced polymer reinforcements for flexural strengthening of concrete structures. Struct. J. 2004, 101, 717-726.

32. Barros, J.A.O.; Dias, S.J.E. Near surface mounted CFRP laminates for shear strengthening of concrete beams. Cem. Concr. Compos. 2006, 28, 276-292. [CrossRef]

33. Nordin, H.; Täljsten, B. Concrete beams strengthened with prestressed near surface mounted CFRP. J. Compos. Constr. 2006, 10, 60-68. [CrossRef]

34. Liu, I.S.T.; Oehlers, D.J.; Seracino, R. Tests on the ductility of reinforced concrete beams retrofitted with FRP and steel near-surface mounted plates. J. Compos. Constr. 2006, 10, 106-114. [CrossRef]

35. Teng, J.G.; de Lorenzis, L.; Wang, B.; Li, R.; Wong, T.N.; Lam, L. Debonding failures of RC beams strengthened with near surface mounted CFRP strips. J. Compos. Constr. 2006, 10, 92-105. [CrossRef]

36. De Lorenzis, L.; Teng, J.G. Near-surface mounted FRP reinforcement: An emerging technique for strengthening structures. Compos. Eng. 2007, 38, 119-143. [CrossRef]

37. Seracino, R.; Raizal Saifulnaz, M.R.; Oehlers, D.J. Generic debonding resistance of EB and NSM plate-to-concrete joints. J. Compos. Constr. 2007, 11, 62-70. [CrossRef]

38. Castro, E.K.; Melo, G.S.; Nagato, Y. Flexural strengthening of RC " $\mathrm{t}$ " beams with near surface mounted (NSM) FRP reinforcements. In Proceedings of International Symposium on FRP Reinforcement of Concrete Structures (FRPRCS-8), Patras, Greece, 16-18 July 2007.

39. Chikh, N.; Foret, G.; Bousalem, B.; Firas, S. Analysis of reinforced concrete members strengthened with near-surface-mounted CFRP. In Proceedings of 11DBMC Conference on Durability of Building Materials and Components, Istanbul, Turkey, 11-14 May 2008.

40. El-Maaddawy, T.A.; El-Dieb, A.S. Near-surface-mounted composite system for repair and strengthening of reinforced concrete columns subjected to axial load and biaxial bending. J. Compos. Constr. 2011, 15, 602-614. [CrossRef] 
41. Sharaky, I.A.; Torres, L.; Comas, J.; Barris, C. Flexural response of reinforced concrete (RC) beams strengthened with near surface mounted (NSM) fibre reinforced polymer (FRP) bars. Compos. Struct. 2013, 109, 8-22. [CrossRef]

42. Bilotta, A.; Ceroni, F.; Barros, J.; Costa, I.; Palmieri, A.; Szabó, Z.; Nigro, E.; Matthys, S.; Balazs, G.; Pecce, M. Bond of NSM FRP-strengthened concrete: Round robin test initiative. J. Compos. Constr. 2015. [CrossRef]

43. Sena Cruz, J.M.; Barros, J.A.O.; Gettu, R.; Azevedo, A.F.M. Bond behavior of near surface mounted CFRP laminate strips under monotonic and cyclic loading. J. Compos. Constr. 2006, 10, 295-303. [CrossRef]

44. Badawi, M.; Soudki, K. Fatigue behavior of RC beams strengthened with NSM CFRP rods. J. Compos. Constr. 2009, 13, 415-421. [CrossRef]

45. Ceroni, F. Experimental performances of RC beams strengthened with FRP materials. Constr. Build. Mater. 2010, 24, 1547-1559. [CrossRef]

46. Ilki, A.; Kumbasar, N. The behavior of damaged reinforced concrete members strengthened by carbon fiber reinforced polymer composites. Tech. J. Turk. Chamb. Civil Eng. 2002, 13, 2597-2616, (In Turkish with English abstract).

47. Bournas, D.A.; Triantafillou, T.C. Flexural strengthening of reinforced concrete columns with near surface mounted FRP or stainless steel. Struct. J. 2009, 106, 495-505.

48. Goksu, C.; Polat, A.; Ilki, A. Attempt for seismic retrofit of existing sub-standard RC members under reversed cyclic flexural effects. J. Compos. Constr. 2012, 16, 286-299. [CrossRef]

49. Fahmy, M.F.M.; Wu, Z. Retrofitting of existing RC square bridge columns using basalt FRP rebars. Available online: http://www.iifc-hq.org/proceedings/CICE_2012/02_FRP\%20in\%20Seismic\%20Retrofitting/02_ 495_Fahmy,Wu_RETROFITTING\%20OF\%20EXISTING\%20RC\%20SQUARE.pdf (accessed on 27 November 2015).

50. Vrettos, I.; Kefela, E.; Triantafillou, T.C. Innovative flexural strengthening of reinforced concrete columns using carbon-fiber anchors. Struct. J. 2013, 110, 63-70.

51. Li, X.; Lv, H.L.; Zhang, G.C.; Sha, S.Y.; Zhou, S.C. Seismic retrofitting of rectangular reinforced concrete columns using fiber composites for enhanced flexural strength. J. Reinf. Plast. Compos. 2013, 32, 619-630. [CrossRef]

52. Goksu, C.; Uzunhasanoglu, A.; Seyhan, E.C.; Ilki, A. Seismic retrofit of sub-standard RC columns with embedded aramid FRP reinforcement. In Proceedings of SMAR 2013 Second Conference on Smart Monitoring, Assessment and Rehabilitation of Civil Structures, Istanbul, Turkey, 9-11 September 2013.

53. Faustino, P.; Chastre, C. Flexural strengthening of columns with CFRP composites and stainless steel: Cyclic behavior. J. Struct. Eng. 2015. [CrossRef]

54. CNR-DT 200/2004. Guide for the design and construction of externally bonded FRP systems for strengthening existing structures. Available online: http://www.cnr.it/documenti/norme/ IstruzioniCNR_DT200_2004_eng.pdf (accessed on 27 November 2015).

55. Akkaya, Y.; Demir, N. Durability issues in existing buildings and new infrastructure projects. In Proceedings of Joint Symposium on Concrete Engineering (JSCE), Istanbul, Turkey, 9 June 2010.

56. Eurocode 8-Part 3. Assessment and retrofitting of buildings. European Committee for Standardization: Brussels, Belgium, 2005.

57. TSDC. Regulations for buildings to be constructed in earthquake prone areas. Turkish Seismic Design Code: Ankara, Turkey, 2007.

58. Eurocode 2: Design of concrete structures. Part 1. General rules and rules for buildings. European Committee for Standardization: Brussels, Belgium, 2004.

59. TS EN 12390-3. Testing hardened concrete-Part 3: Compressive strength of test specimens. Turkish Standards Institute: Ankara, Turkey, 2003.

60. TS 708. Steel bars for concrete. Turkish Standards Institute: Ankara, Turkey, 1996.

61. Part 3: Structural and non-structural repair. In Products and Systems for the Protection and Repair of Concrete Structures. Definitions, Requirements, Quality Control and Evaluation of Conformity; BS EN 1504-3:2005; British Standard Institute: London, UK, 2006.

62. Part 4: Structural bonding. In Products and Systems for the Protection and Repair of Concrete Structures. Definitions, Requirements, Quality Control and Evaluation of Conformity; EN 1504-4:2004; British Standard Institute: London, UK, 2004.

63. TS-EN 196-1. Methods of testing cement-Part 1: Determination of strength. Turkish Standards Institute: Ankara, Turkey, 2009. 
64. ASTM D3039. Standard test method tensile properties of polymer matrix composite materials. ASTM International: West Conshohocken, PA, USA, 2014.

65. Matamoros, A.B.; Sozen, M.A. Drift limits of high-strength concrete columns subjected to load reversals. J. Struct. Eng. 2003, 129, 297-313. [CrossRef]

66. Bournas, D.A.; Triantafillou, T.C. Bond strength of lap spliced bars in concrete confined with composite jackets. J. Compos. Constr. 2011, 15, 156-167. [CrossRef]

67. XTRACT 3.0.8. Cross-sectional structural analysis of components. TRC: Rancho Cordova, CA, USA, 2007.

68. Ilki, A.; Peker, O.; Karamuk, E.; Demir, C.; Kumbasar, N. FRP retrofit of low and medium strength circular and rectangular reinforced concrete columns. J. Mater. Civil Eng. 2008, 20, 169-188. [CrossRef]

69. ACI-318M-14. Metric building code requirements for structural concrete and commentary. American Concrete Institute 318: Farmington Hills, MI, USA, 2014.

70. ACI-355-1R-91. State-of-the-art report on anchorage to concrete. American Concrete Institute 355: Farmington Hills, MI, USA, 1991.

(C) 2015 by the authors; licensee MDPI, Basel, Switzerland. This article is an open access article distributed under the terms and conditions of the Creative Commons by Attribution (CC-BY) license (http:/ / creativecommons.org/licenses/by/4.0/). 